\title{
Factors Analysis of the Electronics Industry Trade Imbalance between the US and China
}

\author{
Jihong $\operatorname{Jin}^{1} \&$ Michael Steffens ${ }^{1}$ \\ ${ }^{1}$ Glorious Sun School of Business and Management, Donghua University, Shanghai, China \\ Correspondence: Michael Steffens, Glorious Sun School of Business and Management, Donghua University, \\ Shanghai. E-mail: A10acskier@aol.com
}

Received: November 15, 2015

Accepted: November 30, 2015 Online Published: December 2, 2015

doi:10.5539/ijms.v7n6p172

URL: http://dx.doi.org/10.5539/ijms.v7n6p172

\begin{abstract}
The US and China trade imbalance is a highly debated topic, and cause of trade conflict between the US and China. One particularly strong area of the trade imbalance is the electronics industry, which as of the year 2013 represented more than $45 \%$ of the total trade balance, the largest subsection of any industry. In order to understand the macroeconomic factors influencing overall trade balance as well as trade balance in the Electronics Industry, this study uses Ordinary Least Squares Regression analysis model to examine how macroeconomic factors such as Exchange Rate, China GDP, US GDP, and CPI affect the trade balance. The results are then compared to an equivalent analysis on the electronics industry using factors such as China Electronics Industry Production, US Electronics Industry Production, Exchange Rate, and CPI. The findings are surprising, showing that the same factors that are traditionally strongly correlated with a change in the overall trade balance, actually have an opposite effect on the Electronics industry trade balance. This paper explores not only what macro economic factors cause the trade imbalances, but also why they happen.
\end{abstract}

Keywords: trade imbalance, Ordinary Least Squares Regression, Foreign Exchange, CPI

\section{Introduction}

The trade imbalance between the US and China is one of the most commonly discussed topics in economic circles, representing not only one of the largest trade imbalance in the world, but also the trade imbalance between the world's two largest economies. This trade imbalance has been a source of conflict and discussion in both the US and China, often times with the US government blaming China for this trade imbalance. Conflict stems from the fact that the US views the ever increasing trade balance as something that causes Americans to lose jobs, weakens US national security, and represents the US losing its more than one hundred year competitive advantage of being the world's strongest manufacturing nation.

The bilateral trade balance has been in a state of continued growth since the opening of the Chinese market by Deng Xiaoping in 1978. China has experienced rapid growth and an economic miracle raising hundreds of millions of people out of poverty, and growing into what is currently considered the world's factory. Growth has also positively impacted the US allowing American consumers to purchase goods at prices previously unimaginable, however many wonder if the drawbacks outweigh the benefits for both sides. One industry sector where this is becoming an issue is electronic goods, viewed as representing high technology, and future business. This concept as well as the dramatically large share of the overall trade deficit that the electronics industry makes up is why this thesis reviews an industry specific trade balance. Using a verified and proven method of econometric analysis, Ordinary Least Squares Regression, this analysis will dive into and uncover the macroeconomic reasons causing the trade imbalance between the US and China. Analysis uses the regression model on both the overall trade balance, as well as the individual electronics industry trade balance, followed by a comparison of the two.

\section{Literature Review}

Before the analysis, a brief introduction of the economic theory of balance of trade is in order. Balance of trade is part of the larger economic unit, the balance of payments. The balance of payments is where countries record monetary transactions with the rest of the world divided into two separate accounts, the current account, as well as capital and financial account. Current account represents goods, services, incomes, and current transfers. The 
capital account represents physical assets such as a building or a factory. The financial account represents assets pertaining to international monetary flows, business or portfolio investments. The largest section of the balance of payments is the current account, "The current account balance is the difference between a country's savings and its investment. [IF the current account balance is] positive, it measures the portion of a country's saving invested abroad, if negative, the portion of domestic investment financed by foreigners savings." The current account balance is defined by the sum of the value of imports of goods and services plus net returns on investments abroad, minus the value of exports of goods and services, where all these elements are measured in the domestic currency (Heakel, 2013). Put simply, the current account balance is essentially the trade balance, and the causes of change in the current account balance is the focus of this research.

In preparation for this analysis, existing research was reviewed in order to act as a baseline, and provide insight on current opinions on the topic. Although most research focuses on exchange rate and overall trade balance only, it helped when determining how to analyze this subsection. Nearly all research on trade balance uses some form of regression model analyze because of the data type. One Chinese scholar used OLS Regression and discovered a weak correlation between Foreign Exchange Rate and the US China overall trade balance, instead because of factors related to labor intensive and resource consuming products (Liang, 2007). A thesis written by another Chinese student using a simple regression analysis instead concludes that the main reason for the trade balance, is simply that US demand for Chinese goods exceeds Chinese demand for American goods (Zhao, 2008). American scholars also have differing viewpoints, one researcher says that China's entry to the WTO, has caused Chinese exports to the US to move up the value chain from previous levels, while US exports to China have gone down the value chain (Casey, 2012).

Existing research shows that despite similar methods of research and essentially identical topics across a broad spectrum, the accurate prediction of the reasoning behind why the trade balance between the US and China exists is up for debate. With the research landscape so uncertain, this research paper will use a different methodology, instead focusing on the largest industry section of the trade imbalance, to further understanding core factors driving this trade imbalance.

\section{History and Current Situation of US China Trade Imbalance}

The trade imbalance between the US and China has been developing for many years, and continues to grow, this is why it has attracted so much attention and been researched so thoroughly in recent years, albeit to no definitive conclusion. The lack of a definitive conclusion is why this paper focuses on the Electronics Industry trade balance, instead using well know methodology and data to focus on the relationship between the overall trade balance and the Electronic Industry. As shown in the graph below, the total US China trade balance has grown to globally unprecedented levels in the previous decade. China's development and increased role in the global economy has created a massive surplus with the US, the world's largest importer and economy in the world.

\section{Overall Trade Balance- China Surplus}

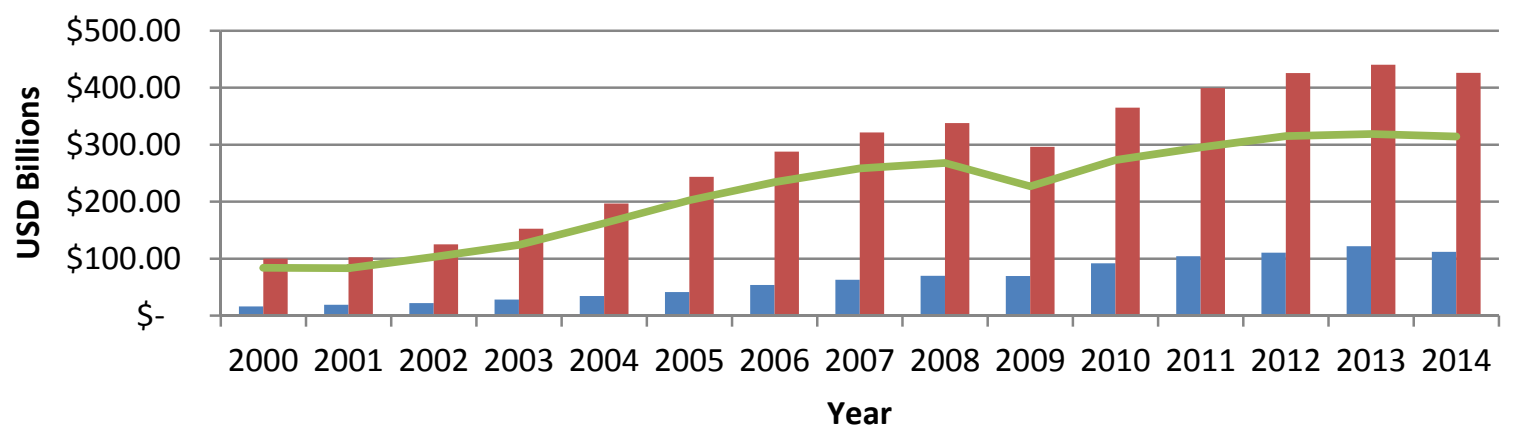

US Exports to China China Exports to US Trade Balance Difference

Figure 1. Overall Trade Balance (US Census Bureau 2000-2014)

While the overall trade balance is alarming, and is trending toward a growing disparity, looking solely at this data does not provide the overall picture. In actuality an extremely large portion of trade balance stems from a 
single industry, the electronics industry. By understanding that the electronics industry alone contributes to nearly 50 percent of the overall balance, analyzing why the electronics industry has been changing can provide more insightful data on the reasoning behind the overall growth. Shown below is the chart that shows the changing trade balance in Electronics.

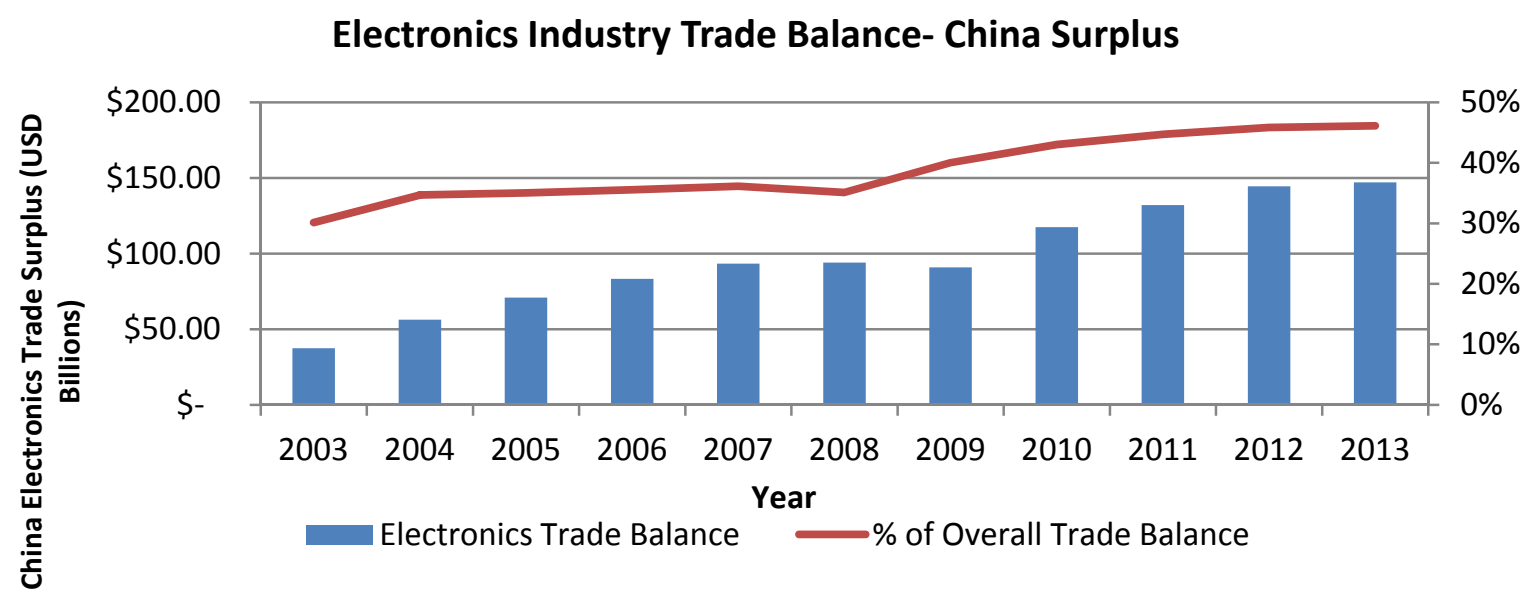

Figure 2. Electronics Trade Balance (US Census Bureau 2003-2013)

Looking at this graph individually, it is apparent that the Electronics Trade balance has grown more uneven step in step with the overall trade balance, but when looking at it as a percentage of overall trade balance, it is clear that this is the main driving force behind overall trade balance change. The question is, how does this industry respond to change in similar macro economic factors, and how does that differ from the overall trade relationship.

\section{Empirical Study}

The follow section shows the quantitative analysis used to analyze macro economic factors and their influence on both the overall US China Trade Balance, as well as the Electronics Industry Trade Balance, which will provide a further understanding of the composition of the trade balance, and driving factors behind it.

\subsection{Method}

The Ordinary Least Squares Regression Model was used to conduct this analysis. OLS was chosen after running the same data through other regression models such as VARS, VECM, and determining that a OLS regression will provide the most accurate and comparable results to other research. Eviews was the program used to provide the output, because of its ability to perform multiple data confirmation tests, as well as run the OLS model.

\subsection{Data Selection and Confirmation Test}

The factors chosen to analyze the trade imbalance, were chosen by looking at similar studies done by well respected scholars. Using several traditional factors that typically correlate with changes in trade balance, analysis was performed on both total trade balance and electronic trade balance. The data and factors come from a variety of different sources such as the US Bureau of Trade Statistics, World Bank, China Industrial Economic Year Book, and a Foreign Exchange website, all data was taken on an annual basis from the years 2003 to 2013.

To verify that all data used in the following regression models fit the required statistical parameters for usage, three different statistical confirmation tests were used. These tests included the Augmented Dickey Fuller Stationary Test, the Granger Causality test, as well as the Engle Granger Co integration test. All data used including the factor data as well as the balance data was first converted using Natural Log, followed by running the statistical tests. The factor and trade balance data all met the requirements necessary to be used in regression analysis. 


\subsection{Constructing OLS Model}

Before beginning the empirical analysis, the regression model was first constructed. Below are two different regression model equations, representing overall trade balance and electronic trade balance. The follow equations set the multiple macroeconomic factors and a constant, against the respective trade balances.

$$
\begin{gathered}
\operatorname{Ln} B=a+b_{1} \ln C N+b_{2} \ln U S+b_{3} \ln F E X+b_{4} \ln C P I \\
L n e B=a+b_{1} \ln e C N+b_{2} \ln e U S+b_{3} \ln e F E X+b_{4} \ln e C P I
\end{gathered}
$$

When

$$
\begin{aligned}
& \text { LnB = US China Trade Balance } \\
& \operatorname{lnCN}=\text { China GDP } \\
& \text { InUS = US GDP } \\
& \text { InFEX = US Dollar to RMB Exchange Rate } \\
& \text { InCPI = CPI difference between US and China } \\
& \text { LneB = US China Electronics Industry Trade Balance } \\
& \text { IneCN = China Electronics Industry Gross Production } \\
& \text { IneUS = US Electronics Industry Gross Production } \\
& \text { IneFEX = US Dollar to RMB Exchange Rate } \\
& \text { IneCPI = CPI difference between US and China }
\end{aligned}
$$

The results of the Ordinary Least Squares analysis provided corresponding coefficient values, which represent how one unit change in each of the factors, will affect overall trade balance.

\subsection{OLS Model Output}

\subsubsection{Overall}

The first output analyzed is the overall trade balance and macroeconomic factors. The results from Eviews indicated a strong model with $\mathrm{R}$ squared at .93, and adjusted $\mathrm{R}$ squared at .86. In order to fully understand the relationship of each individual factor with the trade balance, the factors corresponding $\mathrm{P}$ values were consulted. The $\mathrm{P}$ value represents the probability that the individual factor is statistically significant, and influences the trade balance. Any P Value below .05 represents a statistically significant relationship, or a greater than $95 \%$ probability that it influences the dependant variable. Shown below is a chart summarizing the factors used and their respective $\mathrm{P}$ values.

Table 1. Overall trade balance-factor results

\begin{tabular}{ll}
\hline Factor & P Value \\
\hline China GDP & .3648 \\
CPI Difference & .0936 \\
Foreign Exchange Rate & .1356 \\
USA GDP & .037 \\
\hline
\end{tabular}

Looking at the results of the first analysis, it is clear that the most influential variable is the US GDP, indicating the strongest correlating relationship with trade balance. CPI difference and Foreign Exchange both show a moderately strong relationship with changes in trade balance, while China's GDP is statistically insignificant, barely influencing the overall trade balance.

\subsubsection{Electronics}

The exact same method and model is used to test for the electronics industry trade balance, the only variation is that the dependeant variable is changed to the Electronics Industry trade imbalance, and the factors are likewise changed to the electronics industry specific factors. As with the overall trade balance, the model summary indicates a strong model, with an R Squared of .96, and a nearly equally strong Adjusted R- squared of .93. Once again the $\mathrm{P}$ values are consulted to determine the relationship of the individual factors with the industry trade balance, the summary table is shown below. 
Table 2. Electronics industry trade balance-factor results

\begin{tabular}{ll}
\hline Factor & P Value \\
\hline China Electronics Production & .0019 \\
CPI Difference & .4241 \\
Foreign Exchange Rate & .0133 \\
USA Electronics Production & .7067 \\
\hline
\end{tabular}

Analysis of the $\mathrm{P}$ Values show that in this specific industry, China's Electronics Production is the main change agent in the Electronics Industry Trade Imbalance, likewise Foreign Exchange plays an extremely influential role. Interestingly enough, this differs from the overall trade balance analysis, where China GDP was the weakest factor, and Foreign Exchange only moderately significant. Also, while CPI Difference and US GDP were large factors, in the Electronics Industry specific analysis, CPI difference and US Electronics Production are statistically insignificant.

\subsection{Model Comparison Takeaways}

The results of the two different analyses provide different reasoning for the primary causes of changes in the trade balance. The table below shows the combined results, in order to view them in relationship to each other. There are several insights about the trade balance which can be taken from

Table 3. Factor analysis summary

\begin{tabular}{ll}
\hline Overall Trade Balance (Factors) & Statistically Significant- (Affects Balance Y/N) \\
\hline US GDP & Yes \\
China GDP & No \\
Foreign Exchange Rate & Slightly \\
CPI Difference & Slightly \\
\hline Electronics Trade Balance (Factors) & Statistically Significant- (Affects Balance Y/N) \\
\hline US Electronics Industry Total Production Value & No \\
China Electronics Industry Total Production Value & Yes \\
Foreign Exchange Rate & Yes \\
CPI Difference & No \\
\hline
\end{tabular}

The empirical analysis provides insight and several key takeaways regarding what causes the two different trade imbalances, and why the relationship exists. These takeaways are distinct and different depending on the level of analysis.

\subsubsection{Overall}

1) More sensitive to changes in US GDP than China GDP, because of reliance on China for cheap manufacturing. Growth in US GDP leads to growth in consumption, which leads to higher demand for Chinese goods.

2) Foreign Exchange plays a minor role, but not statistically significant.

3) CPI difference is very influential, explained by the fact that higher inflation in US leads customers to seek cheaper goods which primarily come from China.

4) China GDP is least influential factor because China does significantly influence overall trade balance because of less reliance on US made goods.

\subsubsection{Electronics}

1) China Electronics Production is a determining factor in trade balance, by looking at overall growth of China Electronics Production compared to US. While US production remains stable and China grows, we understand that China production is eating up all the new electronics demand in the US and China.

2) Foreign Exchange also plays a big factor in the electronics trade balance, this is because many electronic components and products are made in China, so fluctuations exacerbate the trade imbalance.

3) CPI difference plays essentially no role in trade imbalance, because while it make affect the overall trade imbalance with things such as food and commodities, electronics are high value high priced products, and 
purchasing decisions as well as manufacturing location decisions are not based on short term changes in CPI difference.

4) US Electronics production has little to no impact on the trade balance, this can be explained that consumption and demand for electronics in the US is relatively stable compared to China.

\section{Conclusions}

While existing research provides a variety of reasons why the US and China trade balance has grown to the levels it has in recent years, research is essentially nonexistent on the industry level. Industry level analysis of the Electronics Industry shows that the same factors that influence overall trade balance, do not necessarily contribute to industry specific changes, in some cases having the completely opposite effect such as GDP and Industry Production levels of countries. Other factors such as Foreign Exchange Rate show slight effects across industry levels. These insights tell us that simply looking at and analyzing factors on the most macro level of overall trade balance is not enough to paint the full picture, or provide the answers on what is actually causing this gigantic trade surplus and deficit. Analysis such as this need to be done on an even more detailed level, looking at individual products in order to solve problems and balance the trade at the more individual level.

In regards to rectifying the Electronics Industry Trade balance, US should encourage China to maintain a free floating currency, that reflects the actual value of the RMB. Additionally, the US should improve domestic production capacity, and encourage American companies currently manufacturing offshore to return to the US through tax breaks and other means necessary to bring back business. China should strengthen Intellectual Property laws, to guarantee the high value assets of the Electronics goods are being produced and developed in China. While these solutions may solve this industries trade balance issues, more analysis needs to be done further breaking down Electronics into products, and other industries in order to provide accurate and feasible solutions on a industry and product level basis. Future research should focus on continuing to breakdown trade balance in smaller sections representing large pieces of the overall balance, instead of simply the most macro scale possible.

\section{References}

Balance of Payments-Financial Account. (2001, September 25). Retrieved October 10, 2014, from http://stats.oecd.org/glossary/detail.asp?ID=158

Bureau of Economic Analysis, U.S. Department of Commerce. (2015). U.S. GDP by Industry 2003-2013. [Data file]. Retrieved July 11, 2015, from http://www.bea.gov/industry/gdpbyind_data.html

Casey, J. (2015). Patterns in U.S.-China Trade since China's Accession to the World Trade Organization. U.S.-China Economic and Security Review Commission Staff Research Report.

China Statistics Press. China Industry Gross Domestic Product 2003-2013. [Data File]. Retrieved from China Industry Economy Statistical Yearbook.

Heakel, R. (2014). Exploring the Current Account in the Balance of Payments. Investopedia. 10 Aug. 2014.

Liang, Z. (2007). The Empirical Analysis of Influencing Factors about Sino-US Trade Surplus. China Technology Online Journal.

Shen, G. (2004). U.S.-China Trade Deficit: An Empirical Research. Technology Time Journal, 1(11), 109-120.

The World Bank, World Development Indicators. (2015). GDP (current US\$) 2003-2013.

The World Bank, World Development Indicators. (2015). Inflation, consumer prices (annual \%).

Thorbecke, W., \& Smith, G. (2010). How Would an Appreciation of the Renminbi and Other East Asian Currencies Affect China's Exports? Review of International Economics, 18(1), 98-105. http://dx.doi.org/10.1111/j.1467-9396.2008.00799.x

US Census Bureau. (2015a). Country Trade Data 2003-2013. Retrieved July 11, 2015, from https://www.census.gov/foreign-trade/statistics/country/index.html

US Census Bureau. (2015b). Product Trade Data 2003-2013. Retrieved July 11, 2015, from https://www.census.gov/foreign-trade/statistics/country/index.html

US RMB Yearly Average Rates. US Forex- Foreign Exchange Services. US Forex, 14 Feb. 2015.

Zhao, L. (2008). Appreciation of RMB affect on US China Trade Surplus - China Comparative Advantage Analysis. Dao Ke Ba Ba. 


\section{Copyrights}

Copyright for this article is retained by the author(s), with first publication rights granted to the journal.

This is an open-access article distributed under the terms and conditions of the Creative Commons Attribution license (http://creativecommons.org/licenses/by/3.0/). 